\title{
XI. On the ensuing opposition of Mars. Read before the astronomical society of London, January 9, 1824
}

\section{F. Baily Esq. F.R.S.}

To cite this article: F. Baily Esq. F.R.S. (1824) XI. On the ensuing opposition of Mars. Read before the astronomical society of London, January 9, 1824, Philosophical Magazine, 63:309, 50-52, DOI: $10.1080 / 14786442408644464$

To link to this article: http://dx.doi.org/10.1080/14786442408644464

曲 Published online: 29 Jul 2009.

Submit your article to this journal $\pi$

山 Article views: 2

Q View related articles $\sqsubset$ 
jects of consideration in the article on liquid substances. Water is an important agent, mechanically and chemically, among those of a volatile nature. Among the gaseous substances, muriatic acid is evolved at all periods of the eruption, and at all temperatures.

Art. IV. Of the Currents of incoherent Lava.

Art. V. Of the Currents of Ashes.

Art. VI. Of the Aggregates formed by those Substances.

Art. VII. Of the Mofette produced by the Carbonic Acid.

Art. VIII. Of Obsidian, a rare Species of Lava at Vesuvius.

In Art. IX. is given A Catalogue of the Products of the Eruption of October 1822 : In Art. X. the Details of the chemical Processes, which they followed in their Analytical Examination of the Substances produced in this last Eruption.

Art. XII. contains two tables of Meteorological Observations made during the months of October and November 1822, at the Observatory of Naples, at the distance of about eight miles from Vesuvius. It also contains a recapitulation of the most remarkable facts observed in the course of the last eruption, and since that period.

The figures represent, 1st, Vesuvius viewed from the road of the Hermitage a few days before the eruption of October $1822 ; 2 \mathrm{~d}$, this eruption observed from the same situation at eight in the evening; 3d, the Volcano seen from Bosco-treCase; 4th, a drawing of the Crater made upon the spot, on the 16 th of November 1822.

XI. On the ensuing Opposition of Mars. By F. BaILY, Esq. F.R.S. Read before the Astronomical Society of London, January 9, 1824.*

A T a time when we have two new and excellent observaA tories established in the southern hemisphere, where the eelestial phænomena are watched and observed with the greatest diligence and zeal, it becomes the more important and necessary that corresponding observations of a certain class of those phænomena, of not very frequent occurrence, should also be made in the northern hemisphere, by such persons as are fortunately possessed of the requisite means for this purpose. Without this co-operation, the labours of those industrious observers will lose much of their value, and the advantageous opportunity of elucidating an important

* See our report of the proceedings of the Society at page 61 . branch 
branch of physical astronomy will be wholly lost to the public.

The ensuing opposition of Mars, on the 24th of March, is one of this class: a phænomenon which occurs once only in a period of about 780 days. It is well known that corresponding observations of this planet, in the two hemispheres, as compared with stars situated near its path, about the period of its opposition, will serve to determine its parallax. And the parallax of Mars being known, that of the sun may thence be deduced. This was the plan adopted by Lacaille, when he was at the Cape of Good Hope, in the year 1751: since which period, the method has fallen into disuse, for want of an observatory in the southern hemisphere, with instruments fit to be compared with those in Europe.

The present period seems extremely favourable (for the reasons above mentioned) for the revival of this method. $\mathrm{At}$ the time of the last opposition in 1822, I ventured to draw the public attention to the subject, by pointing out certain stars, near which the planet would pass; and with the positions of which it might be compared. Several valuable observations were made both in the southern and in the northern hemisphere, which are published in various periodical works: and which, being thus recorded, may be referred to with advantage, by those who devote themselves to this branch of physical astronomy.

At the present opposition, there are but few stars, and those of inferior magnitude, with which Mars can be advantageously compared. For ten days preceding and subsequent to the date of its opposition, Mars will not approach near to any star given in the large catalogues of Bradley or Piazzi. There are, however, five stars given in the catalogues of Lalande, inserted in the Connaissance des Tems for the years VIII. and XIII. with which the comparisons may be made. The mean places of these stars, on January 1 st of the present year, are given in the following little table; together with the dates when Mars will be in conjunction with them.

\begin{tabular}{|c|c|c|c|c|}
\hline Conn. des Tems. & Mag. & $A R$. & D. & Mars. \\
\hline $\begin{array}{l}\text { An. XIII. } \\
\text { XIII. } \\
\text { XIII. } \\
\text { VIII. } \\
\text { XIII. }\end{array}$ & $\begin{array}{c}7 \cdot 8 \\
8 \\
8 \\
7 \\
6 \cdot 7\end{array}$ & $\begin{array}{rrr}\text { H. } & \text { M. } & \text { s. } \\
12 & 10 & 0 \\
& 14 & 29 \\
17 & 16 \\
& 20 & 8 \\
& 29 & 56\end{array}$ & $\begin{array}{ccc}0 & 18 & 44 \\
2 & 18 & 44 \\
1 & 52 & 2 \\
1 & 29 & 47 \\
1 & 8 & 37 \\
0 & 6 & 44\end{array}$ & 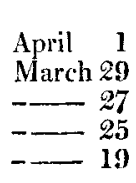 \\
\hline
\end{tabular}


When Mars approaches either of these stars, the observer should, with a micrometer, measure their distance in a direct line; or take the differences, in right ascension and declination, between the planet and the star: the place and the correct time of observation being noted down.

Accurate observations of this kind are of great importance in astronomy: and as nothing tends so much to further such objects as a previous announcement of the phænomena about to take place, I trust I need not make any apology for drawing the attention of the members of this Society to so interesting a subject.

The diameter of Mars, on the day of opposition, will be $13^{\prime \prime}, 91$.

XII. Notices respecting Nerw Books.

\section{Recently published.}

A Practical Essay on the Strength of Cast-Iron and other $M e-$ tals, \&c.; the 2nd Edition, 8vo. By Thomas Tredgold, Civil Engineer, \&c.

THIS importantly useful Work, came under our notice too

late in the last Month, to admit our doing little more in p. 451, than announcing its publication: we now therefore resume the subject, with reference to the account we gave of the 1st Edition, in p. 137 of our 60th volume, in order to notice, the new matters dispersed through the present Edition, which seems collectively to amount to about 130 pages.

Instead of the former seven Sections, the work now consists of eleven such, viz. an entire new sixth Section has been inserted; the matter of the former sixth Section has, with a great deal that is new, been distributed into four others, which are numbered VII, VIII, IX and X, and the former seventh Section is now the XIth. Very judiciously, as regards references, and the quotings of this Work by other Writers (which cannot fail we think of becoming numerous), no alterations have been made of the former division of the Work into 304 Articles, as numbered in the Margin; but between these Arts. in various places, the principal new matter has been introduced, and numbered and distinguished thus, viz. $6^{\mathrm{a}}$, following Art. 6; $8^{\mathrm{a}}$ following Art. 8:19 $19^{\mathrm{a}}$ and $19^{\mathrm{b}}$, following Art. 19, \&c. And the alphabetical Table of Data, which follows Art. 304, might, advantageously for references, have its Articles numbered, in continuation, viz. 305, 306, \&c.; and in a future Edition we hope this will be done. 